\title{
ONTOLOGY DEVELOPMENT FOR SOFTWARE TRACKING INFORMATION SYSTEM
}

\author{
Sumit Kumar Mishra ${ }^{1}$, V.K. Singh ${ }^{2}$ \\ ${ }^{1}$ Assistant Professor, Babu Banarasi Das Northern Indian Institute of Technology, Lucknow, UP \\ mishrasumit221@gmail.com \\ ${ }^{2}$ Professor. \& Head - I.T., Babu Banarasi Das National Institute of Technology \& Management, Lucknow. India
}

\begin{abstract}
Ontology Development For Software tracking Information System makes use of the semantic web and it used for check and track software performance which help for user to retrieve basic information like maximum retail price, information about software and other information like software latest version, Cost price, tracking old issues in software, searching for software price history in previous software.
\end{abstract}

Keyword: RDF, SPARQL, OWL, Web Semantic.

\section{INTRODUCTION}

ontology development for software tracking information system track and check software performance and its availability. In Ontology development for software tracking Information System we develop software information ontology and apply this ontology for information retrieval mechanism as a knowledge base for retrieving and managing acquaintance in a field of Software. $[1,15]$. with the help of this ontology we also check MRP of software.

\section{PROPOSED MODEL}

The Proposed model based on Software information ontology. This ontology build in ontology development tool protege4.3.0 software. This ontology provides for the basic framework of the Software ontology based model. In this information system we used DotNetRDF which is a RDF API used in Microsoft Visual Studio for implementing Semantic Web concepts. A SPARQL and SQL two query language used for this framework SPARQL provide basic semantic concept which is connected DOTNETRDF API and SQL provide database connectivity. $[14,15]$

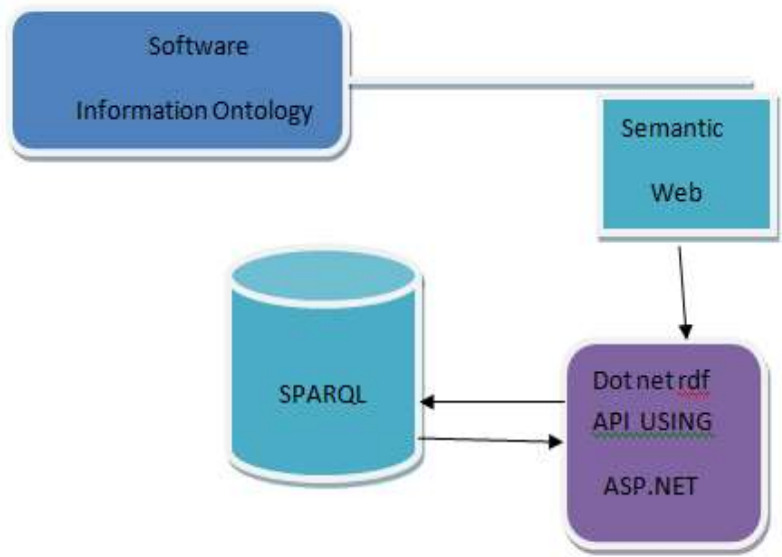

Fig.1. Software tracking information system model

\subsection{Ontology Design}

Ontology basically used for sharing information .ontology consist 4 thing $<\mathrm{C}, \mathrm{I}, \mathrm{R}, \mathrm{A}>[4,5]$.

- $\quad \operatorname{Class}(\mathrm{C})$

- Instances (I)

- $\quad$ Relationship(R)

- Axioms(A)

\section{-PROJECT_Information}
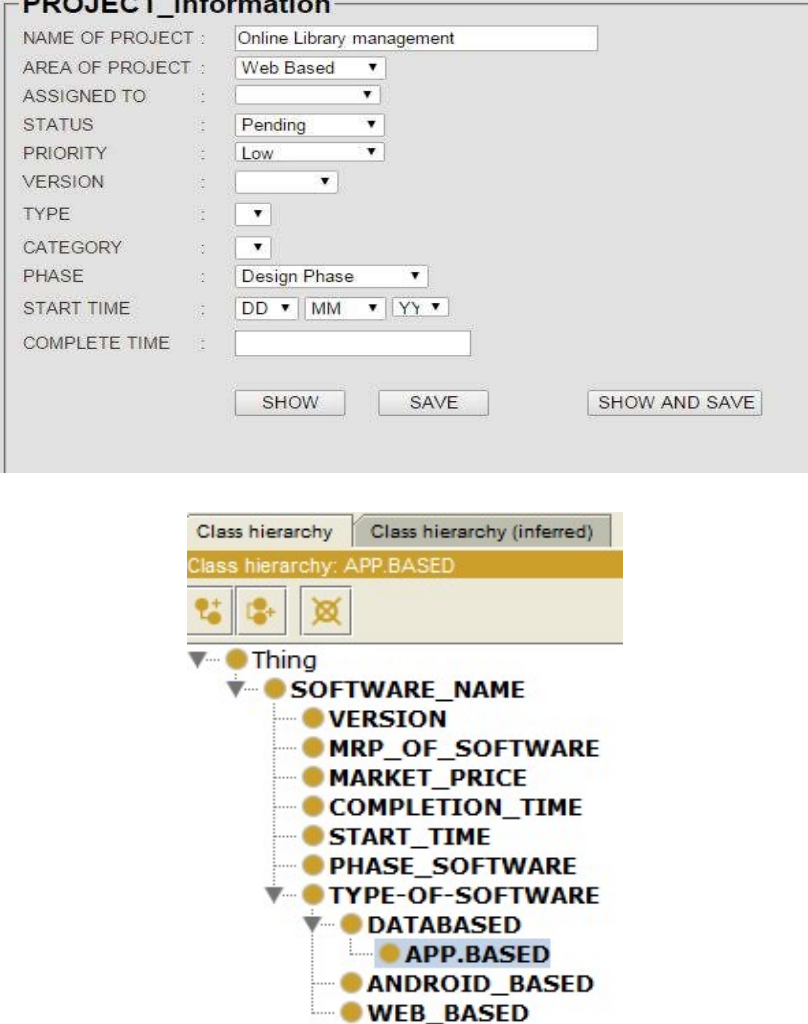

Fig.2, 3 project information \& Class hierarchy software tracking ontology 


\section{SQL LOGIN CONTROL WEB SECURITY USING C\# CODE}

using System;

using System.Collections.Generic;

using System.Linq;

using System.Web;

using System.Web.UI;

using System.Web.UI.WebControls;

using BUG.Database;

using System.Data.SqlClient;

using System.Data;

public partial class homeloginpage : System.Web.UI.Page

\{

SqlDataAdapter da;

DataSet ds = new DataSet();

int flag $=0$;

protected void Page_Load(object sender, EventArgs e) \{

$\mathrm{da}=$ new SqlDataAdapter("select $*$ from account","Data Source=DELL-PC\ISQLEXPRESS; Initial Catalog $=$ softwaresystem;Integrated Security=True");

da.Fill(ds);

\}

protected void Button1_Click(object sender, EventArgs e)

Response.Redirect("Default.aspx");

$$
\begin{aligned}
& \left\{\begin{array}{l}
\text { if }(\text { flag }==0) \\
\text { Label1.Text }=\text { "user name and password not }
\end{array}\right.
\end{aligned}
$$

match";

\subsection{Sparql}

It is also query language.it is used to query to

RDF file.It is quite similar to SQL which is used to query RDBMS

\section{RDF FILE GENERATION CODE USING C\#}

using System;

using System.Collections.Generic;

using System.Linq;

using System.Web;

using System.Web.UI;

using System.Web.UI.WebControls;

using VDS.RDF;

using VDS.RDF.Writing;

using System.Xml;

using VDS.RDF.Parsing;

public partial class_Default : System.Web.UI.Page

\{

static string GUID = "";

protected void Page_Load(object sender, EventArgs e) \{\}

protected void Button1_Click(object sender, EventArgs e)

\{ IGraph g1 = new Graph();

TripleStore store $=$ new TripleStore();

IUriNode hassoftwareId

g1.CreateUriNode(UriFactory.Create("http://www.semantic web.org/dell/ontologies/2015/0/untitled_ontology-

6\#hasSoftwareId"));
IUriNode

hassoftwaretype $=$ g1.CreateUriNode(UriFactory.Create("http://www.semantic web.org/dell/ontologies/2015/0/untitled_ontology6\#hassoftwaretype"));

IUriNode

hasproject $=$ g1.CreateUriNode(UriFactory.Create("http://www.semantic web.org/dell/ontologies/2015/0/untitled_ontology6\#hasproject"));

\section{WORKING OF SOFTWARE}

This interface look like a search engine in which comma separated values are entered also that involves semantic web concept you can find Software information on similar matters by searching through. Like if somebody search "android mobile "also gets consisting of results like "ABC MOBILE “etc.

\section{SOFTWARESEARCH}

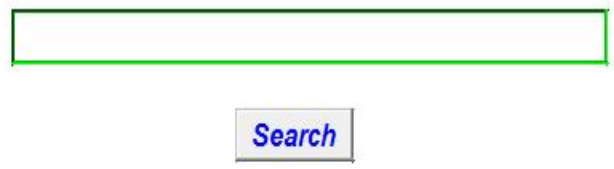

Fig 4. Software search page

\section{CONCLUSION AND FUTURE SCOPE}

The future scope of our work is to apply the potential of Knowledge Representation[12,13,14] along with reasoning in the Web context. The use of semantic web in software tracking Information System helps the machine to take the appropriate decision regarding software and provide appropriate result.

\section{REFERENCES}

[1]. Sumit Kumar mishra, Dr. V.K. Singh Anurag Tiwari“'Ontology development for agriculture research a case study of wheat " journal of basic and applied engineering research

[2]. Six Basic Classes of Wheat Minnesota Association of Wheat Growers.

[3]. Chalkley , D,(2010)," Invasive Fungi: Alternaria leaf blight of Wheat -Alternaria triticina". Systematic mycology and Microbiology laboratory, Agricultural Research Service. Unfitted States Department Of Agriculture Archived From the original on 29 October 2014.

[4]. Natalya F. Noy and Deborah L. McGuinness,

[5]. Ontology Development 101: A Guide for Creating Your First Ontology.

[6]. Toby Segaran, Colin Evans, and Jamie Taylor, -Programming the Semantic Web.

[7]. Gómez-Pérez, A., Fernández-López, M., Corcho, O. Ontological Engineering, with examples from the areas of Knowledge Management, e-Commerce and the Semantic Web. Springer, London, Berlin (2003) 
[8]. Opijnen, Marc van, The European Legal Semantic Web: Completed Building Blocks and Future Work (November 22, 2012). European Legal Access Conference, November 2012.

[9]. Amit Sheth,Cartic Ramakrishnan, and Christopher Thomas, 'Semantics for The Semantic Web: the Implicit, the Formal and the Powerful',International Journal on Semantic Web \& Information Systems, 1 (no. 1), 2005, pp. 1-18.

[10]. 3. Brachman , R.J., McGuinness, D.L., PatelSchneider, P.F., Resnick, L.A. and Borgida, A. (1991). Living with CLASSIC: When and how to use KLONE-like language. Principles of Semantic Networks. J. F. Sowa, editor, Morgan Kaufmann: 401-456

[11]. Legal Semantic Web- A Recommendation System gaurav kant, Gaurav Kant, V.K.Singh, M. Darbari, D. Yagyasen ${ }^{4}, P . K$. Shukla International journal ICANI

[12]. ]Bob DuCharme, Learning SPARQL, O'REILLY, 2011.

[13]. Gómez-Pérez, A., Fernández-López, M., Corcho, O. Ontological Engineering, with examples from the areas of Knowledge Management, e-Commerce and the Semantic Web. Springer, London, Berlin (2003)

[14]. D Yagyasen, M Darbari, P K Shukla, V K Singh,(2013). "Diversity and Convergence Issues in Evolutionary Multi- objective Optimization: Application to Agriculture Science", IERI Procedia, Elsevier.

[15]. D Yagyasen, M Darbari, H Ahmed, (2013). "Transforming Non-Living to Living: A Case on Changing Business Environment", 2013, IERI Procedia, Elsevier.

[16]. S.k.mishra Dr.V.K. Singh Gaurav Kant "Ontology development for Wheat Information System" IJERT.

\section{ABOUT AUTHORS}

SUMIT KUMAR MISHRA received his B.Tech degree from U.P.T.U. in 2013. Currently he is Assistant Professor, Babu Banarasi Das Northern Indian Institute of Technology, Lucknow Uttar Pradesh, India.

Dr. V.K. SINGH Prof. \& Head - I.T., Babu Banarasi Das National Institute of Technology \& Management,Lucknow. India. 